\title{
Decreased handgrip strength can predict lung function impairment in male workers: a cross sectional study
}

\author{
Makiko Kanai ${ }^{1,2^{*}}$ (D), Osamu Kanai ${ }^{2}$, Kohei Fujita ${ }^{2}$, Tadashi Mio $^{2}$ and Masato Ito ${ }^{1}$
}

\begin{abstract}
Background: Spirometry is useful for evaluating respiratory health status and predicting health-related outcomes. As spirometry requires skilled technician and takes time, it is useful to find simple way for predicting lung function impairment. The aim of this study was to investigate which tests could predict lung function impairment among workers.
\end{abstract}

Methods: This prospective study included workers of manufacturing industry who underwent health check-ups in 2017. Subjects underwent the chronic obstructive pulmonary disease (COPD) assessment test (CAT), spirometry, and physical fitness assessments, including handgrip strength (HGS). Lung function impairment was defined as a decline in any of forced expiratory volume in $1 \mathrm{~s}$ (FEV1), forced vital capacity (FVC), or a FEV1/FVC ratio less than the lower limit of normal (LLN).

Results: Complete data on 475 workers (366 men, 50.4\% ever smokers) were available. Lung function impairment was observed in 99 subjects (64 men). Men with lung function impairment had significantly higher rate of eversmoking, passive smoking at home in childhood, high CAT scores, and decreased HGS, compared with those without. On multivariate analyses, ever-smoking (odds ratio [OR], 2.50; 95\% confidence intervals [Cl], 1.25-4.97), passive smoking at home in childhood (OR, 2.71; 95\% Cl, 1.16-6.32), CAT scores (OR, 1.06; 95\% Cl, 1.01-1.12), and HGS $(\mathrm{OR}, 0.73 ; 95 \% \mathrm{Cl}, 0.57-0.92)$ were independently associated with lung function impairment in men.

Conclusions: Ever-smoking, passive smoking at home in childhood, high CAT scores, and decreased HGS are significantly associated with lung function impairment in men.

Trial registration: Registration number: UMIN000028011. Date of registration: July 1, 2017.

Keywords: Spirometry, Hand grip strength, Smoking, Passive smoking

\footnotetext{
* Correspondence: makiko-kanai@umin.ac.jp

${ }^{1}$ Panasonic Health Care Center, Panasonic Health Insurance Organization,

5-55 Sotojima-cho, Moriguchi-city, Osaka 570-0096, Japan

${ }^{2}$ Division of Respiratory Medicine, National Hospital Organization Kyoto

Medical Center, 1-1 Fukakusa-Mukaihata-Cho, Fushimi-Ku, Kyoto 612-8555,

Japan
}

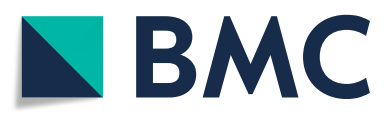

( The Author(s). 2020 Open Access This article is licensed under a Creative Commons Attribution 4.0 International License, which permits use, sharing, adaptation, distribution and reproduction in any medium or format, as long as you give appropriate credit to the original author(s) and the source, provide a link to the Creative Commons licence, and indicate if changes were made. The images or other third party material in this article are included in the article's Creative Commons licence, unless indicated otherwise in a credit line to the material. If material is not included in the article's Creative Commons licence and your intended use is not permitted by statutory regulation or exceeds the permitted use, you will need to obtain permission directly from the copyright holder. To view a copy of this licence, visit http://creativecommons.org/licenses/by/4.0/ The Creative Commons Public Domain Dedication waiver (http://creativecommons.org/publicdomain/zero/1.0/) applies to the data made available in this article, unless otherwise stated in a credit line to the data. 


\section{Background}

Lung function impairment, including chronic obstructive pulmonary disease (COPD), is commonly observed in the general population, but it is often undiagnosed $[1,2]$. Spirometry is useful not only for evaluating respiratory health status but also for predicting health-related outcomes $[3,4]$. Despite this, spirometry is not widely applied in primary care or in health check-ups. This is because the procedure is cumbersome, time-consuming, and tends to be different depending on the ability of the inspector. It would be beneficial to screen subjects who could benefit from spirometry by questionnaire or a simpler examination.

Some simple physical fitness assessments that can be performed in mass screenings have been reported to be associated with a wide range of health-related outcomes. Handgrip strength (HGS) is often used as a low-cost indicator of muscle strength, and it is reported that a lower HGS is associated with a range of health-related outcomes, including all respiratory diseases $[5,6]$. The sit-to-stand (STS) test was reported to be strongly associated with mortality in COPD patients [6]. We hypothesized that such simple physical fitness assessments might be predictors of lung function impairment before disease onset in healthy individuals. In the present study, we investigated which factors, including questionnaires, smoking and passive smoking status, and physical fitness assessments, could predict lung function impairment among workers.

\section{Methods}

\section{Study design}

This prospective study included employees of the manufacturing industry in Uji city, Kyoto, Japan, who underwent annual health check-ups, physical fitness assessments and spirometry in July 3-14, 2017. This study was approved by the Ethics Committee of Panasonic Health Care Center (Approval No. 2017-004) and registered in the UMIN Clinical Trials Registry (No. UMIN000028011) on July 1, 2017. All study participants provided their written informed consent and our study adheres to STROBE Statement.

\section{Measurements}

Physical examination included height $(\mathrm{m})$, weight $(\mathrm{kg})$, and blood pressure $(\mathrm{mmHg})$. Hypertension was defined as systolic blood pressure $\geq 140 \mathrm{mmHg}$ or diastolic blood pressure $\geq 90 \mathrm{mmHg}$ or receiving treatment for hypertension. Blood tests were conducted after an overnight fast and included biochemical measurements of triglycerides (TG), low-density lipoprotein cholesterol (LDL-C) and high-density lipoprotein cholesterol (HDL-C), fasting plasma glucose (FPG), glycated hemoglobin (HbA1c), and uric acid (UA). Diabetes mellitus was defined according to American Diabetes Association criteria of $\mathrm{FPG} \geq 126 \mathrm{mg} / \mathrm{dl}$, $\mathrm{HbA} 1 \mathrm{c} \geq 6.5 \%$, or receiving treatment for diabetes. Dyslipidemia was defined as HDL-C $<40 \mathrm{mg} / \mathrm{dl}, \mathrm{LDL}-\mathrm{C} \geq 140 \mathrm{mg} / \mathrm{dl}, \mathrm{TG} \geq 150 \mathrm{mg} / \mathrm{dl}$ or lipid-specific treatment. Hyperuricemia was defined as $\mathrm{UA} \geq 7.0 \mathrm{mg} / \mathrm{dl}$. Information on medical histories, health status, current use of medications, smoking status, and exposure to risk factors (passive smoking and hospitalization due to respiratory diseases in childhood) was obtained using a self-administered questionnaire. All consenting subjects completed a Japanese version of the COPD assessment test (CAT) questionnaire [7]. Smoking status was classified into current, former, and never smokers. For passive smoking, exposure at work (current and previous) and at home (current and in childhood) were asked separately. Ever passive smoking was defined as being exposed currently or previously either at home or at the workplace. Physical fitness assessments included the HGS test and STS test. HGS was measured using a Smedley-type hand dynamometer (TTM Tokyo, Japan). Two attempts were performed with each hand, and the better value of each hand was used for analysis. The STS test was conducted using a standard chair with no arm rests. The subjects were instructed to stand up from and sit down on the chair without using any supports and repeat the procedure as many times as possible in $30 \mathrm{~s}$ at a self-selected speed. The number of completed repetitions was recorded [6, 8].

\section{Spirometry}

Forced vital capacity (FVC) and forced expiratory volume in the first second of expiration (FEV1) were measured with a calibrated Chestgraph HI-301 U (CHEST M.I., Inc. Tokyo, Japan) according to the recommended method [9]. The predicted and age-specific lower limit of normal (LLN) FVC, FEV1 and FEV1/FVC were calculated using the equations for the Japanese population [10]. Lung function impairment was defined as decline in FEV1, FVC or FEV1/FVC below the LLN.

\section{Statistical analyses}

Subjects' characteristics were summarized as number (percentage) for categorical variables and mean (standard deviation) for continuous variables. Comparisons between groups were examined using Fisher's exact tests for categorical values and Mann-Whitney $U$ tests for continuous values. A $P$ value of less than 0.05 was considered statistically significant, and the confidence intervals $(\mathrm{CI})$ were $95 \%$. The STS test and factors with a $\mathrm{P}$ value of less than 0.05 in the univariate analyses were included in the multivariate logistic regression analyses. Statistical analyses were performed using $\mathrm{R}$ version 3.4.1 ( $\mathrm{R}$ Foundation for Statistical Computing, Vienna, Austria). 
Table 1 Baseline characteristics

\begin{tabular}{|c|c|c|c|c|c|c|c|c|c|}
\hline \multirow[b]{2}{*}{$\mathrm{n}$} & & \multicolumn{2}{|c|}{ Overall } & \multicolumn{2}{|l|}{ Men } & \multicolumn{2}{|c|}{ Women } & \multicolumn{2}{|c|}{$P$ value } \\
\hline & & \multicolumn{2}{|l|}{475} & \multicolumn{2}{|l|}{366} & \multicolumn{2}{|l|}{109} & & \\
\hline Age (years) & & 48.9 & $(9.2)$ & 48.4 & (9.8) & 50.5 & $(6.4)$ & & 0.034 \\
\hline BMI $\left(\mathrm{kg} / \mathrm{m}^{2}\right)$ & & 23.3 & (3.8) & 23.6 & (3.6) & 22.09 & $(4.4)$ & $<$ & 0.001 \\
\hline \multirow[t]{3}{*}{ Smoking status } & current & 129 & $(27.2)$ & 118 & $(32.2)$ & 11 & $(10.1)$ & $<$ & 0.001 \\
\hline & former & 110 & (23.2) & 98 & (26.8) & 12 & $(11.0)$ & & \\
\hline & never & 236 & $(49.7)$ & 150 & $(41.0)$ & 86 & $(78.9)$ & & \\
\hline \multirow[t]{5}{*}{ Passive smoking } & ever passive smoking & 404 & $(85.1)$ & 314 & $(85.8)$ & 90 & (82.6) & & 0.444 \\
\hline & at home currently & 96 & $(20.2)$ & 50 & (13.7) & 46 & $(42.2)$ & $<$ & 0.001 \\
\hline & at home in childhood & 351 & (73.9) & 274 & (74.9) & 77 & (70.6) & & 0.386 \\
\hline & at workplace currently & 47 & $(9.9)$ & 45 & (12.3) & 2 & $(1.8)$ & $<$ & 0.001 \\
\hline & at workplace previously & 153 & $(32.2)$ & 126 & $(34.4)$ & 27 & $(24.8)$ & & 0.062 \\
\hline \multicolumn{2}{|c|}{ Hospitalization due to respiratory diseases in childhood } & 17 & (3.6) & 14 & (3.8) & 3 & $(2.8)$ & & 0.773 \\
\hline \multicolumn{10}{|l|}{ Comorbidities } \\
\hline \multicolumn{2}{|l|}{ Hypertension } & 119 & (25.1) & 101 & $(27.6)$ & 18 & $(16.5)$ & & 0.023 \\
\hline \multicolumn{2}{|l|}{ Diabetes mellitus } & 27 & (5.7) & 21 & (5.7) & 6 & $(5.5)$ & $>$ & 0.999 \\
\hline \multicolumn{2}{|l|}{ Dyslipidemia } & 232 & $(48.8)$ & 187 & $(51.1)$ & 45 & (41.3) & & 0.081 \\
\hline \multicolumn{2}{|l|}{ Hyperuricemia } & 113 & (23.8) & 109 & (29.8) & 4 & (3.7) & $<$ & 0.001 \\
\hline
\end{tabular}

Data are shown in mean (standard deviation) for continuous values and in number (percentage) for categorical values. $P$ values for comparison between sexes are estimated by using Fisher's exact tests or Mann-Whitney $\mathrm{U}$ tests where appropriate

Table 2 Results of spirometry, COPD assessment test, and physical fitness assessments

\begin{tabular}{|c|c|c|c|c|c|c|c|c|}
\hline \multirow[t]{2}{*}{$n$} & \multicolumn{2}{|l|}{ Overall } & \multicolumn{2}{|l|}{ Men } & \multicolumn{2}{|c|}{ Women } & \multicolumn{2}{|c|}{$P$ value } \\
\hline & \multicolumn{2}{|l|}{475} & \multicolumn{2}{|l|}{366} & \multicolumn{2}{|l|}{109} & & \\
\hline \multicolumn{9}{|l|}{ Spirometry } \\
\hline FVC (L) & 3.73 & $(0.77)$ & 4.02 & $(0.59)$ & 2.75 & $(0.41)$ & $<$ & 0.001 \\
\hline \%FVC (\%) & 92.9 & $(11.2)$ & 93.6 & $(11.1)$ & 90.4 & (11.3) & & 0.009 \\
\hline $\mathrm{FVC}<\mathrm{LLN}$ & 70 & $(14.7)$ & 41 & $(11.2)$ & 29 & (26.6) & $<$ & 0.001 \\
\hline FEV1 (L) & 3.07 & $(0.65)$ & 3.31 & $(0.53)$ & 2.29 & $(0.35)$ & $<$ & 0.001 \\
\hline \%FEV1 (\%) & 94.9 & (12.34) & 95.4 & $(12.4)$ & 93.2 & (12.1) & & 0.094 \\
\hline FEV1 < LLN & 68 & $(14.3)$ & 49 & $(13.4)$ & 19 & (17.4) & & 0.28 \\
\hline FEV1/FVC (\%) & 82.6 & $(5.93)$ & 82.4 & $(6.02)$ & 83.6 & (5.54) & & 0.052 \\
\hline \%FEV1/FVC (\%) & 102.02 & $(7.06)$ & 101.73 & (7.15) & 102.98 & (6.69) & & 0.106 \\
\hline FEV1/FVC $<$ LLN & 20 & $(4.2)$ & 15 & $(4.1)$ & 5 & $(4.6)$ & & 0.789 \\
\hline Lung function impairment & 99 & $(20.8)$ & 64 & $(17.5)$ & 35 & (32.1) & & 0.002 \\
\hline \multicolumn{9}{|l|}{ Questionnaire } \\
\hline COPD assessment test & 8.85 & $(5.45)$ & 9.02 & $(5.31)$ & 8.29 & $(5.91)$ & & 0.223 \\
\hline \multicolumn{9}{|l|}{ Physical fitness assessments } \\
\hline Handgrip strength (kg) & 40.78 & $(10.22)$ & 45.17 & $(6.60)$ & 26.06 & $(5.25)$ & $<$ & 0.001 \\
\hline Sit-to-stand test (times) & 29.45 & $(6.80)$ & 29.81 & $(6.60)$ & 28.25 & $(7.34)$ & & 0.036 \\
\hline
\end{tabular}

Data are shown in mean (standard deviation) for continuous values and in number (percentage) for categorical values. P values for comparisons between sexes are estimated by using Fisher's exact tests or Mann-Whitney $U$ tests where appropriate

Lung function impairment was defined as a decline in FEV1, FVC or FEV1/FVC less than the LLN. Ever passive smoking was defined as being exposed currently or previously either at home or at the workplace

FVC forced vital capacity, FEV1 forced expiratory volume in $1 \mathrm{~s}$, LLN lower limit of normal 


\section{Results}

The study consisted of 475 subjects (366 men and 109 women) who agreed to participate in the research and underwent spirometry and physical fitness assessments. The mean age and standard deviation were 48.9 and 9.2 years old. Current, former and never smokers were 32, 27 , and $41 \%$ in men and 10,11 , and $79 \%$ in women, respectively (Table 1). The prevalence of current exposure to passive smoking at home and in the workplace was 14 and $12 \%$ in men and 42 and $2 \%$ in women, respectively $(P<0.001$ and $<0.001)$. The comorbidity rates of hypertension and hyperuricemia were significantly higher in men than in women $(28 \%$ versus $17 \% ; P=0.023$, and $30 \%$ versus $4 \% ; P<0.001$, respectively).

The results of spirometry, CAT scores, and physical fitness assessments are shown in Table 2. Lung function impairment was observed in $18 \%$ of men and $32 \%$ of women $(P=0.002)$. The mean CAT score was 9.02 in men and 8.29 in women $(P=0.223)$. The HGS of men was significantly higher than that of women $(45.2 \mathrm{~kg}$ versus $26.1 \mathrm{~kg} ; \mathrm{P}<0.001$ ), while no significant difference was observed in the results of the STS test (29.8 times in men and 28.3 times in women; $P=0.036$ ).

Due to significant differences in baseline characteristics between sexes, we analyzed predictive factors for lung function impairment by sex. Comparisons between men with lung function impairment and those without lung function impairment were significantly different with respect to the following factors (Table 3): ever smoking $(73 \%$ vs $56 \% ; P=0.011)$, ever passive smoking ( $94 \%$ vs $84 \% ; P=0.048$ ), passive smoking at home in childhood ( $89 \%$ vs $72 \% ; P=0.004$ ), passive smoking at home currently ( $22 \%$ vs $12 \% ; P=0.045)$, CAT score (11 vs $8.6 ; P=0.001$ ), and HGS $(43.1 \mathrm{~kg}$ vs $45.6 \mathrm{~kg} ; P=$ $0.005)$. In women, the rate of hospitalization due to respiratory diseases in childhood was higher in those with lung function impairment than in those without (9\% vs $0 \% ; P=0.031$ ), while dyslipidemia was more frequent in those without lung function impairment (49\% vs $26 \%$; $P=0.036$ ). Distribution of HGS by gender are shown in Fig. 1.

We performed initial multivariate analyses adjusted for smoking status, CAT score, HGS, STS test and ever passive smoking (Model 1) and performed secondary analyses adjusted for passive smoking at home currently and in childhood instead of all types of passive smoking (Model 2). Ever smoking, high CAT scores, and decreased HGS were independently associated with lung function impairment in both models (Table 4A). Regarding passive smoking, only passive smoking at home in childhood was significantly associated with lung function impairment (odds ratio, 2.71; 95\% confidence intervals, 1.16-6.32; $P$ value, 0.021 ). In women, no significant association was found between predictive factors detected by univariate analyses and lung function impairment (Table 4B).

Table 3 Univariate analyses of predictive factors for any lung function impairment stratified by sex

\begin{tabular}{|c|c|c|c|c|c|c|c|c|c|c|c|c|}
\hline \multirow{3}{*}{$\begin{array}{l}\text { Sex } \\
\text { Lung function impairment } \\
\mathrm{N}\end{array}$} & & \multicolumn{5}{|l|}{ Men } & \multicolumn{6}{|c|}{ Women } \\
\hline & & \multirow{2}{*}{\multicolumn{2}{|c|}{$\frac{\mathrm{No}}{302}$}} & \multicolumn{2}{|l|}{ Yes } & \multirow[t]{2}{*}{$P$ value } & \multicolumn{2}{|l|}{$\overline{N o}$} & \multicolumn{2}{|l|}{ Yes } & \multicolumn{2}{|c|}{$P$ value } \\
\hline & & & & 64 & & & 74 & & 35 & & & \\
\hline Age (years) & & 52 & [19-62] & 53 & [19-60] & 0.785 & 52 & [21-60] & 52 & {$[26-57]$} & & 0.896 \\
\hline BMI (kg/m2) & & 23.1 & [17.4-39.0] & 23.45 & {$[17.0-40.6]$} & 0.727 & 22 & [16.1-42.3] & 20.8 & [15.6-30.4] & & 0.14 \\
\hline Smoking status & ever & 169 & $(56.0)$ & 47 & $(73.4)$ & 0.011 & 7 & $(9.5)$ & 4 & $(11.4)$ & & 0.743 \\
\hline Passive smoking & ever & 254 & $(84.1)$ & 60 & (93.8) & 0.048 & 61 & $(82.4)$ & 29 & $(82.9)$ & $>$ & 0.999 \\
\hline \multirow[t]{2}{*}{ at home } & currently & 36 & (11.9) & 14 & (21.9) & 0.045 & 1 & (1.4) & 1 & $(2.9)$ & & 0.541 \\
\hline & in childhood & 217 & (71.9) & 57 & $(89.1)$ & 0.004 & 18 & $(24.3)$ & 9 & $(25.7)$ & $>$ & 0.999 \\
\hline \multirow[t]{2}{*}{ while working } & currently & 34 & (11.3) & 11 & $(17.2)$ & 0.209 & 33 & $(44.6)$ & 13 & $(37.1)$ & & 0.536 \\
\hline & previously & 99 & $(32.8)$ & 27 & $(42.2)$ & 0.192 & 51 & $(68.9)$ & 26 & $(74.3)$ & & 0.656 \\
\hline \multicolumn{2}{|c|}{ Hospitalization due to respiratory diseases in childhood } & 10 & (3.3) & 4 & $(6.2)$ & 0.28 & 0 & $(0.0)$ & 3 & $(8.6)$ & & 0.031 \\
\hline \multicolumn{2}{|l|}{ Hypertension } & 78 & $(25.8)$ & 23 & $(35.9)$ & 0.123 & 12 & $(16.2)$ & 6 & $(17.1)$ & $>$ & 0.999 \\
\hline \multicolumn{2}{|l|}{ Diabetes mellitus } & 16 & $(5.3)$ & 5 & $(7.8)$ & 0.387 & 5 & $(6.8)$ & 1 & $(2.9)$ & & 0.662 \\
\hline \multicolumn{2}{|l|}{ Dyslipidemia } & 152 & $(50.3)$ & 35 & $(54.7)$ & 0.583 & 36 & $(48.6)$ & 9 & $(25.7)$ & & 0.036 \\
\hline \multicolumn{2}{|l|}{ Hyperuricemia } & 88 & $(29.1)$ & 21 & $(32.8)$ & 0.551 & 2 & $(2.7)$ & 2 & $(5.7)$ & & 0.592 \\
\hline \multicolumn{2}{|c|}{ COPD assessment score } & 8.6 & $(4.95)$ & 11.0 & $(6.42)$ & 0.001 & 7.8 & $(4.74)$ & 9.4 & $(7.8)$ & & 0.169 \\
\hline \multicolumn{2}{|c|}{ Handgrip strength (kg) } & 45.6 & $(6.11)$ & 43.1 & $(8.29)$ & 0.005 & 26.4 & $(5.79)$ & 26.37 & $(3.85)$ & & 0.374 \\
\hline \multicolumn{2}{|c|}{ Sit to stand test (times) } & 30.0 & $(6.58)$ & 28.8 & $(6.69)$ & 0.2 & 28.5 & $(7.31)$ & 27.8 & $(7.5)$ & & 0.644 \\
\hline
\end{tabular}

Data are shown in mean and (standard deviation) for continuous values and in number and (percentage) for categorical values. $P$ values for comparisons between respiratory dysfunction or not were estimated by using Fisher's exact tests or Mann-Whitney U tests where appropriate 
A

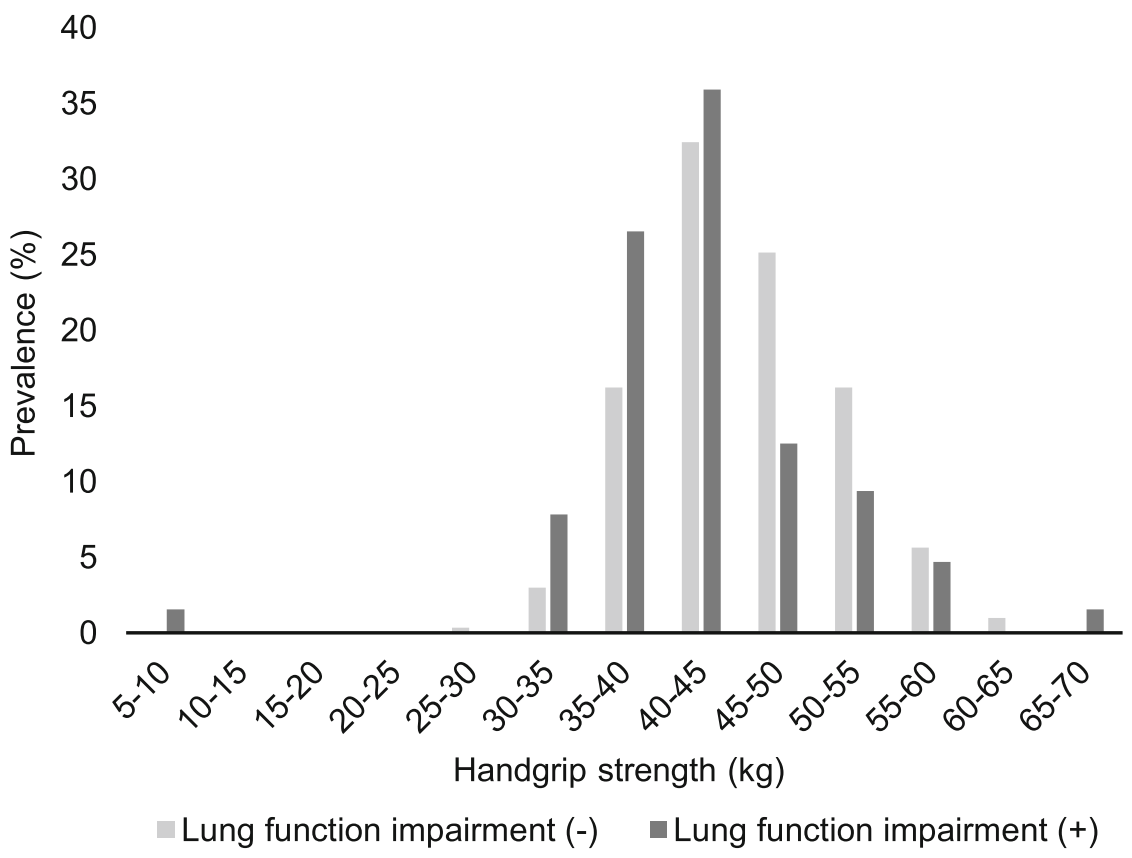

B

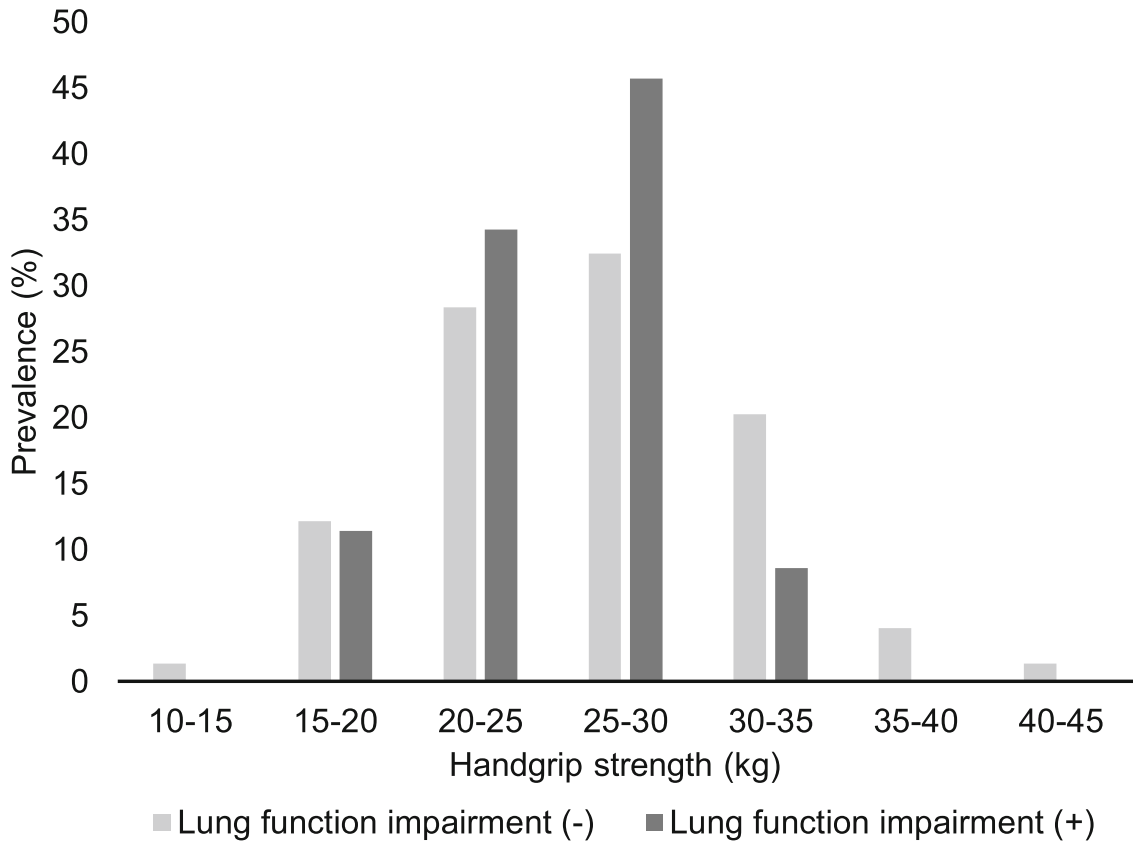

Fig. 1 Distribution of handgrip strength classified by the presence of lung function impairment. These histograms show the distribution of handgrip strength in men (a) and women (b). Bars colored dark gray indicate the prevalence of each levels of handgrip strength in participants with lung function impairment, while bars colored light gray indicate those in participants without lung function impairment

\section{Discussion}

We revealed that decreased HGS was associated with lung function impairment. However, we did not find any significant difference between lung function impairment and the STS test, which is useful for evaluating functional status in patients with COPD [8]. This may result from abundant evidence that low HGS was associated with allcause mortality and with a wide range of poorer health outcomes, including all respiratory diseases [5, 11]. Regarding COPD, $65.4 \%$ of patients with COPD had decreased HGS, and it was associated with respiratory events [12]. Simple functional performance tests, such as the 
Table 4 Multivariate analyses of predictive factors for lung function impairment

\begin{tabular}{|c|c|c|c|c|c|c|}
\hline \multicolumn{7}{|l|}{ A: Men } \\
\hline \multirow[b]{2}{*}{ Factors } & \multirow[b]{2}{*}{ Odds ratio } & \multicolumn{3}{|l|}{ Model 1} & \multicolumn{2}{|l|}{ Model 2} \\
\hline & & $95 \% \mathrm{Cl}$ & $P$ value & Odds ratio & $95 \% \mathrm{Cl}$ & $P$ value \\
\hline Smoking status (ever versus never) & 2.67 & $(1.35-5.27)$ & 0.0046 & 2.5 & $(1.25-4.97)$ & 0.0093 \\
\hline COPD assessment score & 1.06 & $(1.01-1.12)$ & 0.022 & 1.06 & $(1.01-1.12)$ & 0.03 \\
\hline Handgrip strength (per 5 kg) & 0.74 & $(0.58-0.94)$ & 0.013 & 0.73 & $(0.57-0.92)$ & 0.011 \\
\hline Sit to stand test (per one time) & 0.99 & $(0.94-1.03)$ & 0.51 & & & \\
\hline Ever passive smoking & 2.31 & $(0.77-6.89)$ & 0.14 & & & \\
\hline Present passive smoking at home & & & & 1.74 & $(0.83-3.68)$ & 0.15 \\
\hline Passive smoking at home in childhood & & & & 2.71 & $(1.16-6.32)$ & 0.021 \\
\hline \multicolumn{7}{|l|}{ B: Women } \\
\hline Factors & Odds ratio & $95 \% \mathrm{Cl}$ & $P$ value & & & \\
\hline Smoking status (ever versus never) & 0.94 & $(0.31-2.81)$ & 0.91 & & & \\
\hline Hospitalization due to respiratory diseases in childhood & $25,900,000$ & $(0.00-\ln f)$ & 0.99 & & & \\
\hline Dyslipidemia & 0.47 & $(0.17-1.24)$ & 0.13 & & & \\
\hline Handgrip strength (per 5 kg) & 0.99 & $(0.91-1.08)$ & 0.78 & & & \\
\hline Sit to stand test (per one time) & 0.97 & $(0.91-1.04)$ & 0.39 & & & \\
\hline
\end{tabular}

Odds ratios and $P$ values were estimated by using logistic regression analyses adjusted by age, BMI, and smoking history (ever smoking or not). In men, model 1 is adjusted for smoking status, CAT score, hand grip strength, Sit to stand test and all types of passive smoking, while model 2 is adjusted for present and previous passive smoking at home instead of all types of passive smoking. CAT; COPD assessment test, Cl; confidence intervals.

HGS and the STS tests, were reported to be useful for predicting mortality and health-related quality of life in COPD patients $[6,12]$. Although there is abundant literature on the association between lung function and HGS, most of them have been studied in the elderly or have investigated the association between disease that has already developed and HGS [13, 14]. In a general population, there are a number individuals with reduced FEV1 and FVC levels, and they have a poorer survival rate than those with normal spirometry results [15]. Therefore, it is important to identify those who can benefit from spirometry before disease onset in general practice. In the present study, odds ratio per $5 \mathrm{~kg}$ higher HGS was 0.73 (95\% confidence intervals, $0.57-0.92 ; P=0.0092$ ) for lung function impairment and we showed that HGS was independently associated with lung function impairment among healthy male workers. Our findings suggest that HGS is a useful tool for identifying those with lung function impairment among healthy subjects who will benefit from further respiratory health assessments. Since HGS is an easy, lowcost and reproducible measurement in general practice, it is worthy of further investigation.

In the present study, we demonstrated that both ever smoking and passive smoking at home in childhood could predict lung function impairment in men. Smoking accelerates the decline of FEV1 and is the strongest risk factor for airflow obstruction [16]. Moreover, smoking during adolescence, the late stage of pulmonary growth, impairs both FEV1 and FVC development [17]. Passive smoking is also known to increase the risk of COPD, and subjects reporting previous passive smoking showed significantly declined FEV1 and FVC rates [18]. Longitudinal studies have revealed that the acceleration of the rate of decline in the FEV1 level and early expression of chronic respiratory symptoms are induced by childhood events and exposures in both smokers and nonsmokers [19]. Parental smoking also increases susceptibility to the ill effects for active smokers and affects early lung function deficits in adulthood [20]. In addition to these previous reports, our findings suggest the importance of asking about the history of passive smoking as well as smoking status to identify lung function impairment.

The CAT is a simple questionnaire that was originally developed to measure health-related quality of life and monitor COPD [21, 22]. The total CAT score is reported to have a significant association with a diagnosis of COPD [23, 24]. The CAT is suggested to be useful for screening respiratory health even in an unselected population, and a significant negative correlation between the CAT score and FEV1, FVC, and the FEV/FVC ratio has been reported in the literature $[22,25]$. In our study, the CAT score was significantly higher in those with lung function impairment than in those without. The most reliable estimate of the minimum important difference of the CAT is reported as 2 points [26], and the 
difference observed in our study is considered to have clinical importance. We found that the CAT score was significantly associated with FEV1 $<$ LLN, FVC $<$ LLN, and $\mathrm{FEV} 1 / \mathrm{FVC}<\mathrm{LLN}$ in men. A higher CAT score may be useful not only for predicting airway obstruction but also for predicting lung function impairment.

There were some limitations. The causal relationship between decreased HGS and lung function impairment is unknown. The present study is a cross-sectional study, and a longitudinal survey is required. Another reason is that there are too many factors contributing to HGS to explain the mechanisms of this relationship. That is, HGS is a marker for nutritional status [27] and is influenced by physical activity $[28,29]$ and lifestyle factors. In women, we found that HGS was not a significant predictor of lung function impairment. A possible reason for this is that there were not enough subjects to detect a significant difference.

\section{Conclusions}

In the present study, we showed that ever smoking, passive smoking at home in childhood, high CAT scores, and decreased HGS can predict lung function impairment in male workers. Further longitudinal investigation is needed to understand the association of HGS and lung function.

\section{Abbreviations}

BMI: Body mass index; CAT: COPD assessment test; COPD: Chronic obstructive pulmonary disease; FEV1: Forced expiratory volume in $1 \mathrm{~s}$; FPG: Fasting plasma glucose; FVC: Forced vital capacity; HbA1c: Glycated haemoglobin; HGS: Handgrip strength; HDL-C: High-density lipoprotein cholesterol; LDL-C: Low-density lipoprotein cholesterol; LLN: Lower limits of normal; STS: Sit-to-stand; TG: Triglyceride; UA: Uric acid

\section{Acknowledgements}

We would like to thank Ms. Chiemi Moriki and Ms. Masami Murasawa (Health care station of Uji, Panasonic Health Care Center, Panasonic Health Insurance Organization) for data management and American Journal Experts (http:// www.aje.com) for their help with English language editing.

\section{Authors' contributions}

MK: study conception and design, data acquisition, data analysis and interpretation, manuscript drafting, critical manuscript revision. OK: study conception and design, data analysis and interpretation, manuscript drafting. KF: study conception and design, manuscript drafting. TM: study conception and design, data analysis and interpretation. Ml: data acquisition, critical manuscript revision. All authors read and approved the final manuscript.

\section{Funding}

This study was supported in part by a grant from the Devices Solution Business Division Uji, Automotive \& Industrial Systems Company, Panasonic Corporation for spirometry and the National Hospital Organization's fiduciary funds for English editing.

\section{Availability of data and materials}

Because the company in which we conducted the survey has been identified, personal information can be leaked by providing raw data. Therefore, we cannot provide the raw data.

\section{Ethics approval and consent to participate}

This study was approved by the Ethics Committee of Panasonic Health Care Center (Approval No. 2017-004) and all study participants provided their written informed consent.

\section{Consent for publication}

Not applicable.

\section{Competing interests}

The authors declare that they have no competing interests.

Received: 8 April 2019 Accepted: 6 April 2020

Published online: 20 April 2020

References

1. C.H. Martinez, D.M. Mannino, F.A. Jaimes, J.L. Curtis, M.L.K. Han, N.N. Hansel, A.A. Diaz, Undiagnosed obstructive lung disease in the United States associated factors and long-term mortality, Ann Am Thorac Soc 12 (2015) 1788-1795. https://doi.org/10.1513/AnnalsATS.201506-3880C.

2. Fukuchi $Y$, Nishimura $M$, Ichinose $M$, Adachi $M$, Nagai $A$, Kuriyama $T$, Takahashi K, Nishimura K, Ishioka S, Aizawa H, Zaher C. COPD in Japan: the Nippon COPD epidemiology study. Respirology. 2004;9:458-65.

3. H.M. Lee, H. Le, B.T. Lee, V.A. Lopez, N.D. Wong, Forced vital capacity paired with Framingham risk score for prediction of all-cause mortality, Eur Respir J 36 (2010) 1002-1006. https://doi.org/10.1183/09031936.00042410.

4. P.G.J. Burney, R. Hooper, Forced vital capacity, airway obstruction and survival in a general population sample from the USA, Thorax. 66 (2011) 49-54. https:// doi.org/10.1136/thx.2010.147041.

5. C.A. Celis-Morales, P. Welsh, D.M. Lyall, L. Steell, F. Petermann, J. Anderson, S. Iliodromiti, A. Sillars, N. Graham, D.F. Mackay, J.P. Pell, J.M.R. Gill, N. Sattar, S.R. Gray, Associations of grip strength with cardiovascular, respiratory, and cancer outcomes and all cause mortality: prospective cohort study of half a million UK biobank participants, BMJ. 361 (2018) 1-10. https://doi.org/10. 1136/bmj.k1651

6. M.A. Puhan, L. Siebeling, M. Zoller, P. Muggensturm, G. ter Riet, Simple functional performance tests and mortality in COPD, Eur Respir J 42 (2013) 956-963. https://doi.org/10.1183/09031936.00131612.

7. T. Tsuda, R. Suematsu, K. Kamohara, M. Kurose, I. Arakawa, R. Tomioka, T. Kawayama, T. Hoshino, H. Aizawa, Development of the Japanese version of the COPD assessment test, Respir Investig 50 (2012) 34-39. https://doi.org/ 10.1016/j.resinv.2012.05.003.

8. S. Ozalevli, A. Ozden, O. Itil, A. Akkoclu, Comparison of the sit-to-stand test with 6 min walk test in patients with chronic obstructive pulmonary disease, Respir Med 101 (2007) 286-293. https://doi.org/10.1016/j.rmed.2006. 05.007.

9. M.R. Miller, R. Crapo, J. Hankinson, V. Brusasco, F. Burgos, R. Casaburi, A. Coates, P. Enright, C.P.M. van der Grinten, P. Gustafsson, R. Jensen, D.C. Johnson, N. MacIntyre, R. McKay, D. Navajas, O.F. Pedersen, R. Pellegrino, G. Viegi, J. Wagner, General considerations for lung function testing, Eur Respir J 26 (2005) 153-161. https://doi.org/10.1183/09031936.05.00034505.

10. M. Kubota, H. Kobayashi, P.H. Quanjer, H. Omori, K. Tatsumi, M. Kanazawa, Reference values for spirometry, including vital capacity, in Japanese adults calculated with the LMS method and compared with previous values, Respir Investig 52 (2014) 242-250. https://doi.org/10.1016/j.resinv.2014.03.003.

11. D.P. Leong, K.K. Teo, S. Rangarajan, P. Lopez-Jaramillo, A.J. Avezum, A. Orlandini, P. Seron, S.H. Ahmed, A. Rosengren, R. Kelishadi, O. Rahman, S. Swaminathan, R. Iqbal, R. Gupta, S.A. Lear, A. Oguz, K. Yusoff, K. Zatonska, J. Chifamba, E. Igumbor, V. Mohan, R.M. Anjana, H. Gu, W. Li, S. Yusuf, Prognostic value of grip strength: findings from the prospective urban rural epidemiology (PURE) study, Lancet. 386 (2015) 266-273. https://doi.org/10. 1016/S0140-6736(14)62000-6.

12. C.H. Martinez, A.A. Diaz, C.A. Meldrum, M.L.N. McDonald, S. Murray, G.L. Kinney, J.E. Hokanson, J.L. Curtis, R.P. Bowler, M.K. Han, G.R. Washko, E.A. Regan. Handgrip strength in chronic obstructive pulmonary disease. Associations with acute exacerbations and body composition. Ann. Am. Thorac. Soc. 14 (2017) 1638-1645. https://doi.org/10.1513/AnnalsATS. 201610-8210C.

13. E. Sillanpää, L. Stenroth, A.Y. Bijlsma, T. Rantanen, J.S. McPhee, T.M. MadenWilkinson, D.A. Jones, M. V. Narici, H. Gapeyeva, M. Pääsuke, Y. Barnouin, J.Y. Hogrel, G.S. Butler-Browne, C.G.M. Meskers, A.B. Maier, T. Törmäkangas, S. Sipilä. Associations between muscle strength, spirometric pulmonary 
function and mobility in healthy older adults, Age (Omaha). 36 (2014). https://doi.org/10.1007/s11357-014-9667-7.

14. T.R.L. Lima, V.P. Almeida, A.S. Ferreira, F.S. Guimarães, A.J. Lopes, Handgrip Strength and Pulmonary Disease in the Elderly: What is the Link?, Aging Dis. 10 (2019) 1109. https://doi.org/10.14336/ad.2018.1226.

15. P. Lange, Spirometric findings as predictors of survival, Thorax. 66 (2011) 1-2. https:/doi.org/10.1136/thx.2010.151274.

16. R. Hooper, P. Burney, W.M. Vollmer, M.A. McBurnie, T. Gislason, W.C. Tan, A. Jithoo, A. Kocabas, T. Weltee, A.S. Buist, Risk factors for COPD spirometrically defined from the lower limit of normal in the BOLD project, Eur Respir J 39 (2012) 1343-1353. https://doi.org/10.1183/09031936.00002711.

17. Gold D, Wang X, Wypij D, Speizer F, Ware J, Dockery D. Effects of cigarette smoking on lung function in adolescent boys and girls. N Engl J Med. 1996; 335:931-7.

18. S. Hagstad, A. Bjerg, L. Ekerljung, H. Backman, A. Lindberg, E. Ronmark, B. Lundback, Passive smoking exposure is associated with increased risk of COPD in never smokers, Chest. 145 (2014) 1298-1304. https://doi.org/10. 1378/chest.13-1349.

19. F.D. Martinez, Early-life origins of chronic obstructive pulmonary disease, N Engl J Med 375 (2016) 871-878. https://doi.org/10.1056/NEJMra1603287.

20. S. Guerra, D.A. Stern, M. Zhou, D.L. Sherrill, A.L. Wright, W.J. Morgan, F.D. Martinez, Combined effects of parental and active smoking on early lung function deficits: a prospective study from birth to age 26 years, Thorax. 68 (2013) 1021-1028. https://doi.org/10.1136/thoraxjnl-2013-203538.Combined.

21. P.W. Jones, G. Harding, P. Berry, I. Wiklund, W.H. Chen, N. Kline Leidy, Development and first validation of the COPD assessment test, Eur Respir J 34 (2009) 648-654. https://doi.org/10.1183/09031936.00102509.

22. N. Gupta, L.M. Pinto, A. Morogan, J. Bourbeau, The COPD assessment test: a systematic review, Eur Respir J 44 (2014) 873-884. https://doi.org/10.1183/ 09031936.00025214

23. N. Gupta, L. Pinto, A. Benedetti, P. Li, W. Tan, S. Aaron, K. Chapman, J. FitzGerald, P. Hernandez, D. Marciniuk, F. Maltais, D. O'Donnell, D. Sin, B. Walker, J. Bourbeau, The COPD assessment test: can it discriminate across COPD subpopulations?, Chest. 150 (2016) 1069-1079. https://doi.org/10. 1016/j.chest.2016.06.016

24. N. Raghavan, Y.M. Lam, K.A. Webb, J.A. Guenette, N. Amornputtisathaporn, R. Raghavan, W.C. Tan, J. Bourbeau, D.E. O'Donnell, Components of the COPD assessment test (CAT) associated with a diagnosis of COPD in a random population sample, J Chronic Obstr Pulm Dis 9 (2012) 175-183. https://doi. org/10.3109/15412555.2011.650802.

25. H. Demirci, K. Eniste, E.O. Basaran, G. Ocakoglu, Z. Yilmaz, S. Tuna, A multicenter family practitioners' research on chronic obstructive pulmonary disease screening using the COPD assessment test, Prim Heal Care Res Dev 18 (2017) 603-607. https://doi.org/10.1017/S1463423617000408.

26. S.S. Kon, J.L. Canavan, S.E. Jones, C.M. Nolan, A.L. Clark, M.J. Dickson, B.M. Haselden, M.I. Polkey, W.D. Man, Minimum clinically important difference for the COPD assessment test: a prospective analysis, Lancet Respir Med 2 (2014) 195-203. https://doi.org/10.1016/S2213-2600(14)70001-3.

27. P.M. Norman K, Stobäus N, Gonzalez MC, Schulzke JD, Hand grip strength: outcome predictor and marker of nutritional status., Clin Nutr. 30 (2011) 135-142. https://doi.org/10.1016/j.cInu.2010.09.010.

28. M. Hamer, E. Stamatakis, Screen-based sedentary behavior, physical activity, and muscle strength in the English longitudinal study of ageing, PLoS One 8 (2013) 4-8. https://doi.org/10.1371/journal.pone.0066222.

29. J. Gianoudis, C.A. Bailey, R.M. Daly, Associations between sedentary behaviour and body composition, muscle function and sarcopenia in community-dwelling older adults, Osteoporos Int 26 (2015) 571-579. https://doi.org/10.1007/s00198-014-2895-y.

\section{Publisher's Note}

Springer Nature remains neutral with regard to jurisdictional claims in published maps and institutional affiliations.

Ready to submit your research? Choose BMC and benefit from:

- fast, convenient online submission

- thorough peer review by experienced researchers in your field

- rapid publication on acceptance

- support for research data, including large and complex data types

- gold Open Access which fosters wider collaboration and increased citations

- maximum visibility for your research: over $100 \mathrm{M}$ website views per year

At BMC, research is always in progress.

Learn more biomedcentral.com/submissions 